\title{
Nexus and Imbroglio: CCAMLR, the Madrid Protocol and Designating Antarctic Marine Protected Areas in the Southern Ocean
}

\author{
Laurence Cordonnery, Alan D. Hemmings and Lorne Kriwoken
}

\begin{abstract}
The paper examines the process and context of international efforts to designate MPAs in the Southern Ocean. The relationship between the CAMLR Convention and the Madrid Protocol is examined in relation to legal, political and administrative norms and practices. A contextual overview of the Antarctic marine protected area system is considered followed by overlapping competencies of CCAMLR and the Madrid Protocol. The Antarctic MPA debate is placed in a wider international legal context of the management of global oceans space in areas beyond national jurisdiction. We provide an analysis of the politico-legal discourse and point to complicating factors within, and external to, the Antarctic system. The concluding section suggests options for breathing new life into the Southern Ocean MPA discourse.
\end{abstract}

\section{Keywords}

Antarctic, Areas Beyond National Jurisdiction (ABNJ), Marine Protected Areas (MPAs), Southern Ocean, CCAMLR, Madrid Protocol

\section{Introduction}

The Southern Ocean encircling the Antarctic continent has a northern boundary ordinarily defined by the Antarctic Convergence or Polar Front, variably occurring between $45^{\circ}$ to $60^{\circ}$ South latitude. ${ }^{1}$ The primary regional instrument for managing the Southern Ocean, the Convention on the Conservation of Antarctic Marine Living Resources ${ }^{2}$ (CAMLR Convention) defines its area of application as this area. ${ }^{3}$ The Southern Ocean so defined covers approximately 32 million $\mathrm{km}^{2}$ (Figure 1). ${ }^{4}$ To put this in context, this area is just under $10 \%$ of the global marine area, more than twice the area of the Arctic Ocean or the Antarctic continent itself. ${ }^{5}$

The Southern Ocean supports an abundance of phytoplankton, krill, fish, seabirds and marine mammals. Historically a very remote region of the world, parts have accordingly escaped significant localised anthropogenic impacts

\footnotetext{
${ }^{1}$ Although the International Hydrographic Organization in 2000 considered restricting "Southern Ocean" to waters south of $60^{\circ}$ South latitude, coincident with the area of the Antarctic Treaty (Washington, 1 December 1959, in force 23 June 1961) 402 UNTS 71.

2 Convention on the Conservation of Antarctic Marine Living Resources (Canberra, 20 May 1980, in force 7 April 1982) 19 ILM 841.

3 Article I: "This Convention applies to the Antarctic marine living resources of the area south of $60^{\circ}$ South latitude and to the Antarctic marine living resources of the area between that latitude and the Antarctic Convergence which form part of the Antarctic marine ecosystem".

4 JP Croxall and S Nicol, 'Management of Southern Ocean Fisheries: global forces and future sustainability' (2004) 16 Antarctic Science 569-584.

5 K Dodds and AD Hemmings 'Polar Oceans: Sovereignty and the Contestation of Territorial Resource Rights' in HD Smith, JL Suárez de Vvero and TS Agardy (ed), Routledge Handbook of Ocean Resources and Management (Routledge, New York, 2015) 576-591.
} 
(although subject to anthropogenic climate change effects) and these areas now represent some of the last largely intact marine ecosystems on the planet. In contrast, some species of the Southern Ocean marine ecosystem have been highly exploited, including seals, whales, marbled rock cod and Patagonian toothfish. ${ }^{6}$ A 2012 assessment of challenges to future conservation of the Antarctic, published in the journal Science noted that:

The most immediate conservation threats to species, ecosystems, and resources around the Antarctic margin are consequences of regional warming, ocean acidification, and changes in sea-ice distribution. Marine resource extraction may exacerbate these threats ... Advancing marine ecosystem protection, which may help ensure that resource extraction is conducted in a more sustainable fashion, is a major governance challenge. ${ }^{7}$

The cutting edge of current Antarctic governance discussion within the Antarctic Treaty System (ATS) ${ }^{8}$ concerns the acceptability and modalities of the application of a longstanding established Antarctic environmental management tool (area protection) ${ }^{9}$ to the Antarctic marine environment as Antarctic Marine Protected Areas (MPAs). ${ }^{10}$

At the global level, the role of MPAs ${ }^{11}$ in biodiversity conservation has been recognised under, inter alia, the Convention on Biological Diversity, ${ }^{12}$ and at the

\footnotetext{
${ }^{6}$ AJ Constable, WK de la Mare, DJ Agnew, I Everson and D Miller, 'Managing fisheries to conserve the Antarctic marine ecosystem: Practical implementation of the Convention on the Conservation of Antarctic Marine Living Resources (CCAMLR)' (2000) 57 ICES Journal of Marine Science 778791.

${ }^{7}$ SL Chown, JE Lee, KA Hughes, J Barnes, PJ Barrett, DM Bergstrom, P Convey, DA Cowan, K Crosbie, G Dyer, Y Frenot, SM Grant, D Herr, MC Kennicutt II, M Lamers, A Murray, HP Possingham, K Reid, MJ Riddle, PG Ryan, L Sanson, JD Shaw, MD Sparrow, C Summerhayes, A Terauds and DH Wells, 'Challenges to the future conservation of the Antarctic' (2012) 337 Science 158-159.

8 '“Antarctic Treaty system' means the Antarctic Treaty, the measures in effect under that Treaty, its associated separate international instruments in force and the measures in effect under those instruments", Article 1, Protocol on Environmental Protection to the Antarctic Treaty (Madrid, 4 October 1991, in force 14 January 1998) 30 ILM 1461.

9 See generally: L Goldsworthy and AD Hemmings 'The Antarctic Protected Area Approach' in S Hart (ed) Shared Resources: Issue of Governance, IUCN Environmental Policy and Law Paper No. 72 (IUCN, Gland, 2008) 105-128.

10 Particularly in relation to annual discussion of the Ross Sea MPA proposal in Antarctic diplomatic fora since 2011: AD Hemmings, 'The Antarctic Treaty System' (2012) 9 New Zealand Yearbook of International Law [2011] 335-340; AD Hemmings, 'The Antarctic Treaty System' (2013) 10 New Zealand Yearbook of International Law [2012] 237-243; AD Hemmings, 'The Antarctic Treaty System' (2015) 11 New Zealand Yearbook of International Law [2013] 270-277; ${ }^{11}$ IUCN defines MPAs as: "A clearly defined geographical space, recognised, dedicated and managed, through legal or other effective means, to achieve the long-term conservation of nature with associated ecosystem services and cultural values". See J Day, N Dudley, M Hockings, G Holmes, D Laffoley, S Stolton and S Wells Guidelines for Applying the IUCN Protected Area Management Categories to Marine Protected Areas (IUCN, Gland, 2012) at 12.

12 Convention on Biological Diversity (Rio de Janeiro, 5 June 1992, in force 29 December 1993) 1760 UNTS 79. Article 8 addresses protected areas; Article 22 requires that " 2 . Contracting Parties shall implement this Convention with respect to the marine environment consistently with the rights and obligations of States under the law of the sea".
} 
2002 World Summit on Sustainable Development (WSSD). ${ }^{13}$ Contemporary integrated oceans management supports the designation of MPAs as an "integral component" and "a principal means of implementing ecosystem-based management" at national or regional levels. ${ }^{14}$ The global situation in relation to MPAs in areas beyond national jurisdiction (ABNJ) is comprehensively reviewed in a by Petra Drankier, ${ }^{15}$ and the key conservation parameters by Graham J. Edgar et al. ${ }^{16}$

As the prime regional institution concerned with management of the Southern Ocean, the ATS through CCAMLR was the obvious mechanism through which the WSSD goal of designating a series of MPAs by 2012 would be met in the Southern Ocean. The CAMLR Commission is mandated under the Convention to, inter alia, designate "the opening and closing of areas, regions or sub-regions for purposes of scientific study or conservation, including special areas for protection and scientific study" through what are termed "conservation measures". ${ }^{17}$ More recently, MPA work under CCAMLR auspices has included workshops, mapping, identification of priority areas and the designation in 2009 of the South Orkney Islands Southern Shelf MPA. However, despite this activity less than 1 per cent of the Southern Ocean has been declared an MPA or a marine reserve. As such, the Southern Ocean lacks systematic MPA representation over the range of marine biogeographic regions. ${ }^{18}$

As the result of policy choice by Antarctic states, the debate around Antarctic MPAs has been substantively confined to CCAMLR fora and situated within the area of responsibility of CAMLR's Commission and its advisory Scientific Committee. However, there are capacities under another ATS component instrument, the Protocol on Environmental Protection to the Antarctic Treaty (Madrid Protocol). Annex V of the Madrid Protocol (Area Protection and

\footnotetext{
${ }^{13}$ See Paragraph 32 (c) of the Plan of Implementation of the World Summit on Sustainable Development: "Develop and facilitate the use of diverse approaches and tools, including the ecosystem approach, the elimination of destructive fishing practices, the establishment of marine protected areas consistent with international law and based on scientific information, including representative networks by 2012 and time/area closures for the protection of nursery grounds and periods, proper coastal land use and watershed planning and the integration of marine and coastal areas management into key sectors" (emphasis added) http://www.un.org/esa/sustdev/documents/WSSD_POI_PD/English/WSSD_PlanImpl.pdf ${ }^{14}$ KN Scott, 'Integrated Oceans Management: A New Frontier in Marine Environmental Protection' in DR Rothwell, AG Oude Elferink, KN Scott and T Stephens (ed) The Oxford Handbook of the Law of the Sea (Oxford University Press, Oxford, 2015) 463-490, 484.

15 P Drankier, 'Marine Protected Areas in Areas beyond National Jurisdiction' (2012) 27 The International Journal of Marine and Coastal Law 291-350.

${ }^{16}$ GJ Edgar, RD Stuart-Smith, TJ Willis, S Kininmonth, SC Baker, S Banks, NS Barrett, MA Becerro, ATF Bernard, J Berkhout, CD Buxton, SJ Campbell, AT Cooper, M Davey, SC Edgar, G Forsterra, DE Galván, AJ Irigoyen, DJ Kushner, R Moura, PE Parnell, NT Shears, G Soler, EMA Strain and RJ Thomson, 'Global conservation outcomes depend on marine protected areas with five key features' (2014) 506 Nature 216-220.

17 CAMLR Convention Article IX.

18 See generally: C Brooks, 'Competing values on the Antarctic high seas: CCAMLR and the challenge of marine-protected areas' (2013) 3 The Polar Journal 277-300; KN Scott, 'Marine Protected Areas in the Southern Ocean' in EJ Molenaar, AG Oude-Elferink and DR Rothwell (eds.) The Law of the Sea and the Polar Regions: Interactions between Global and Regional Regimes (Martinus Nijhoff, Leiden, 2013) 113-137.
} 
Management) enables "any area, including any marine area" to be designated as an Antarctic Specially Protected Area (ASPA) or Antarctic Specially Managed Area (ASMA). Although small marine areas, and marine areas forming part of immediately adjacent terrestrial ASPAs and ASMAs, continue to be designated under the Madrid Protocol, this mechanism has been effectively closed in relation to larger MPAs. The concurrence of CCAMLR required under Article 6.2 of Annex V states:

[h] aving regard to the provisions of Articles 4 and 5 of the Protocol, no marine area shall be designated as an Antarctic Specially Protected Area or an Antarctic Specially Managed Area without the prior approval of the Commission for the Conservation of Antarctic Marine Living Resources.

This has in practice resulted in total capture of the prerogative of considering MPAs by CCAMLR.

The purpose of this article is to examine the process and context of international efforts to designate MPAs in the Southern Ocean. We consider the relationship between the CAMLR Convention and the Madrid Protocol with particular attention to the legal, political and administrative norms and practices. This is followed by a contextual overview of the Antarctic MPA system, wherein the one successful MPA designation (of the South Orkney Islands Southern Shelf) and two other (so far unsuccessful) MPA proposals (the Ross Sea and waters off East Antarctica) are briefly considered. The overlapping competences of CCAMLR and the Madrid Protocol - the nexus between the two instruments - are then assessed. The present Antarctic MPA imbroglio is placed in its wider international legal context of the management of global ocean space in areas beyond national jurisdiction (ABNJ). An analysis of the politico-legal discourse follows, in which we try to point to the complicating factors both within, and external to, the Antarctic system, and thus the lessons that may be drawn from the MPA imbroglio that has developed in recent years. In the concluding section we suggest options for breathing new life into the Southern Ocean MPA discourse.

\section{The Relationship between CCAMLR and the Madrid Protocol}

\section{The nexus between conservation and exploitation of resources}

Both the CAMLR Convention and the Madrid Protocol constitute legal responses to perceived threats from increasing human activity in the Antarctic region. They were adopted to address issues not covered under the Antarctic Treaty, in relation to environmental protection and resource exploitation. But the nexus between environmental protection and exploitation is dealt with differently under each instrument. Despite this, there are important areas of overlap and potentially concurrent claims for competence between the two instruments.

The negotiations that led to the adoption and then abandonment of the Convention on the Regulation of Antarctic Mineral Resource Activities 
(CRAMRA), ${ }^{19}$ and the adoption in its place of the Madrid Protocol in 1991 were driven by the intense debate around the acceptability, character and duration of a prohibition on the exploitation of mineral resources. Antarctic Treaty Consultative Parties (ATCPs) struggled to find a compromise between those states seeking a perpetual mining ban and those seeking to keep the possibility of opening up the region to mineral activities. ${ }^{20}$ The Madrid Protocol offers a compromise, specifying that "[a]ny activity relating to mineral resources, other than scientific research, shall be prohibited". ${ }^{21}$ This prohibition can be lifted following a review process that may commence fifty years after the Madrid Protocol entered into force, ${ }^{22}$ that is in 2048. There is, however, no imperative for a review process to be triggered, in which case the Madrid Protocol, including the minerals prohibition continues.

Having set aside the issue of mineral resource exploitation, the Madrid Protocol focuses on the regulation of human activities (particularly scientific and logistic activities, but for the first time also tourist activities) and the minimisation of impacts upon the Antarctic environment. In addition to its environmental principles and environmental management tools the Protocol establishes a set of standards and processes detailed in (now) six Annexes. ${ }^{23}$ Article 3(2) (a) states that "activities in the Antarctic Treaty Area shall be planned and conducted so as to limit adverse impact on the Antarctic environment and dependent and associated ecosystems". It is assumed that all human activities are likely to cause an impact on the environment and parties must undertake an environmental impact assessment (EIA) before activities can proceed (Article 3(2) (c)). ${ }^{24}$

Fishing activities in the Southern Ocean that fall within the area of application of the Antarctic Treaty (and thus of the Madrid Protocol) have not been subject to EIA or other Madrid Protocol requirements. This has been affirmed through several mechanisms within the Madrid Protocol: The Final Act of the Eleventh Special Antarctic Treaty Consultative Meeting which adopted the Madrid Protocol seeks to exempt CCAMLR activities from Article 8 of the Protocol, which establishes the EIA requirement. ${ }^{25}$ Article 8 itself only applies the obligation to

\footnotetext{
${ }^{19}$ Convention on the Regulation of Antarctic Mineral Resource Activities (Wellington, 2 June 1988, not in force) 27 ILM 868.

${ }^{20}$ See C Joyner, 'The Antarctic minerals negotiating process' (1987) 81 American Journal of International Law 888-905.

${ }^{21}$ Madrid Protocol, Article 7. The main instrument and four of its five original technical annexes entered into force on 14 January 1998; the fifth Annex entered into force 24 May 2002.

22 See Article 25 of the Madrid Protocol.

${ }^{23}$ Annex I Environmental Impact Assessment; Annex II Conservation of Antarctic Fauna and Flora (already revised but with that revision not yet in force); Annex III Waste Disposal and Waste Management; Annex IV Prevention of Marine Pollution; Annex V Area Protection and Management; and Annex VI Liability Arising from Environmental Emergencies (not yet in force) ${ }^{24}$ On EIA under the Madrid Protocol see: AD Hemmings and LK Kriwoken, 'High level Antarctic EIA under the Madrid Protocol: State practice and the effectiveness of the Comprehensive Environmental Evaluation process' (2010) 10 International Environmental Agreements: Politics, Law and Economics 187-208 at 188-192.

25 "With respect to the activities referred to in Article 8, the Meeting noted that it was not intended that those activities should include activities undertaken in the Antarctic Treaty area pursuant to the Convention on the Conservation of Antarctic Marine Living Resources or the Convention for the Conservation of Antarctic Seals". Final Act of the Eleventh Special Antarctic
} 
conduct EIA to those activities "for which advance notice is required under Article VII (5) of the Antarctic Treaty", and with the short lived exception of New Zealand, no state has included fishing (or whaling) activities in its advance notification. ${ }^{26}$ Similarly, the environmental principles enshrined in Article 3 are also tied to the activity being subject to Article VII (5) of the Antarctic Treaty. ${ }^{27}$

The main driver behind CCAMLR's negotiation in the late 1970s was the concern that unregulated exploitation of krill (Euphasia superba) would jeopardize the Antarctic marine ecosystem. As a result, an ecosystem approach was adopted within CCAMLR, ${ }^{28}$ rather than the then normal single species approach inherent in most international fisheries agreements. Whilst the CAMLR Convention aimed to provide more than a fisheries management organization for the Antarctic, the ecosystem approach it pioneered has been adopted to some extent in the subsequent development of Regional Fisheries Management Organizations (RFMOs) globally.

The ecosystem approach represents the accommodation of interests between conservation and fishing states through management principles combining resource exploitation with environmental protection: fishing is permitted, but conservation measures aiming to ensure a sustainable exploitation of resources apply. The ecosystem approach is also reflected in the area of application of the Convention, which is the ecosystem boundary formed by the Antarctic Convergence. The convergence coincides with the area where warmer waters of the Southern Ocean meet cold waters of the Antarctic; it is defined as a line varying between 60 degrees south and 45 degrees south, which means that CCAMLR's area of application extends beyond the limits to which the Antarctic Treaty applies. ${ }^{29}$ Further, fisheries management under CCAMLR incorporates the precautionary principle. ${ }^{30}$ The application of the precautionary approach requires that the absence of sufficient information shall not preclude decisions being made. In the absence of scientific data upon which fisheries management decisions could be made, the implementation of the precautionary principle has been difficult, at least during the first 10 years of the Commission's operations. Indeed, no precautionary catch limits on krill were adopted until 1991.

\section{Institutional mechanisms and decision-making}

The establishment of a permanent structure to give effect to CCAMLR's aims and objectives created a precedent in the context of the wider ATS. CCAMLR had,

\footnotetext{
Treaty Consultative Meeting:

http://www.ats.aq/documents/keydocs/vol_1/vol1_3_AT_Final_Act_Eleventh_SATCM_e.pdf

${ }^{26}$ AD Hemmings, KR Scott and M Rogan-Finnemore, 'Broadening the duty in relation to

Environmental Impact Assessment across the legal instruments applying in Antarctica' (2007) 11

IHLRes (28 June 2007), http://www.worldlii.org/cgi-

bin/download.cgi/download/int/journals/IHLRes/2007/11.rtf

27 Madrid Protocol, Article 3(4).

28 See, e.g., CCAMLR, Article I (3), Article II(3).

${ }^{29}$ See CCAMLR, Article I (4).

${ }^{30}$ L Cordonnery, 'Environmental Protection in Antarctica: Drawing lessons from the CCAMLR

model for the implementation of the Madrid Protocol' (1998) 29 Ocean Development \&

International Law 125-146.
} 
from inception, a Secretariat that gathers scientific information derived from fishing activities, a supervisory Commission and an advisory Scientific Committee. ${ }^{31}$ On the basis of the scientific information and advice provided by the Scientific Committee, at its annual meeting the Commission reviews existing conservation measures and formulates, and adopts (by consensus) new conservation measures. Conservation measures regulate the opening and closing of areas and seasons for fishing, impose total allowable catch numbers for harvested species and implement other restrictions such as mesh size or gear type. ${ }^{32}$ Compliance with conservation measures is generally high, but is of course dependent upon adequate independent monitoring, and variable levels of domestic enforcement.

Under the Madrid Protocol, the Committee for Environmental Protection (CEP) is both the main advisory body to the Antarctic Treaty Consultative Meeting (ATCM) and charged with "formulat[ing] recommendations to the Parties in connection with the implementation of the Protocol ...". It is the primary operational working group within which environmental duties and needs are considered. ${ }^{33}$ Generally, recommendations from the CEP are adopted by the Plenary session of the ATCM without substantive amendment. However, the CEP as such has no standing to "veto" or "authorize" state action.

It is worth contrasting here the institutional provisions of the Madrid Protocol with the Draft Convention on Antarctic Conservation promoted during the Protocol's negotiations by Environmental Non-Governmental Organisations (ENGOs) under the umbrella of the Antarctic and Southern Ocean Coalition (ASOC). ${ }^{34}$ ASOC argued for strong institutional arrangements to give effect to a

\footnotetext{
31 These institutional arrangements are defined in Article XIII of CCAMLR for the Secretariat, in Articles VII, VIII and IX for the Commission, and in Articles XIV-XVI for the Scientific Committee. 32 It is worth noting here that since 1991, the Commission has gradually expanded the scope of the conservation measures by attempting to minimise the incidental mortality of seabirds in the course of longline fishing in the Convention area. The Commission has introduced the use of VMS for all fishing vessels in the Convention area since 1997. An observation and inspection system has also been introduced by the Commission as part of the enforcement mechanisms, as expressed in Article XXIV of CCAMLR and was first in operation during the 1989/1990 season. 33 The objective of the CEP is to provide advice and formulate recommendations on the implementation of the Madrid Protocol, including the operation of its Annexes, for consideration at ATCMs. In particular Article 12 of the Madrid Protocol details the items on which the CEP is to deliver its advice as follows: (a) the effectiveness of measures taken pursuant to this Protocol; (b) the need to update, strengthen or otherwise improve such measures; (c) the need for additional measures, including the need for additional Annexes, where appropriate; (d) the application and implementation of the environmental impact assessment procedures set out in Article 8 and Annex I; (e) means of minimising or mitigating environmental impacts of activities in the Antarctic Treaty area; (f) procedures for situations requiring urgent action, including response action in environmental emergencies; $(\mathrm{g})$ the operation and further elaboration of the Antarctic Protected Area system; (h) inspection procedures, including formats for inspection reports and checklists for the conduct of inspections; (i) the collection, archiving, exchange and evaluation of information related to environmental protection; ( $j$ ) the state of the Antarctic environment; and $(\mathrm{k})$ the need for scientific research, including environmental monitoring, related to the implementation of this Protocol.

${ }^{34} \mathrm{ASOC}$ is a non-profit organisation including more than 200 conservation groups in 49 countries around the world. In November 1990, in recognition of its stature as the leading environmental advocate for the Antarctic region, ASOC was granted observer status at the meetings of the ATCPs.
} 
comprehensive Antarctic environmental protection regime, and tabled a Draft Convention at the Special Consultative Meeting, ${ }^{35}$ as a model for an environmental protection regime. The institutional arrangements proposed were similar to those of CCAMLR, including: an Antarctic Conservation Commission (which would have adopted decisions by a three-quarters vote), an Environmental, Scientific, Safety and Technical Committee, and an Antarctic inspectorate. ${ }^{36}$ Such proposals were unsuccessful, although some greater institutional capacity was subsequently provided by the establishment of an Antarctic Treaty Secretariat in 2003.37

\section{The issue of Antarctic sovereignty and implications for fisheries management}

Article VI of the Antarctic Treaty introduces some qualification of the application of the treaty to the high seas. ${ }^{38}$ The high seas of the Southern Ocean and the resources therein fall under the system of ocean governance detailed in the 1980 United Nations Convention on the Law of the Sea (LOSC). ${ }^{39}$ Under LOSC, territorial sovereignty is a prerequisite to the application of sovereign rights over adjacent ocean space. ${ }^{40}$ But, in accordance with Article IV of the Antarctic Treaty, territorial claims on the Antarctic continent are frozen and therefore cannot in practice be used, inter alia, to assert coastal state rights over the ocean space adjacent to such territorial claims. The unresolved nature of territorial sovereignty on the Antarctic continent and surrounding islands south of $60^{\circ}$ south latitude thereby precludes the application of marine management delimitations in force elsewhere. More precisely, the concept of the Coastal State described in LOSC and its rights and duties in relation to Territorial Seas, Exclusive Economic Zones and the Continental Shelf have not been readily applicable in the Antarctic Treaty Area. Consequently, for most states, the high seas of the Southern Ocean begin at the edge of the Antarctic continent. ${ }^{41}$ Because of these special circumstances, the management of human activity is conducted here through a patchwork of ATS and LOSC elements.

This complex situation has not prevented some Antarctic claimant states ${ }^{42}$ from asserting attributes of coastal state sovereignty in the Southern Ocean through

\footnotetext{
35 ASOC, 'The Convention on Antarctic Conservation', Information Paper 56, XI Antarctic Treaty Special Consultative Meeting, Viña Del Mar, Chile, 19 November - 6 December 1990.

${ }^{36}$ See DJ Bederman, 'The Antarctic and Southern Ocean Coalition's Convention on Antarctic Conservation' (1991) 4 The Georgetown International Environmental Law Review 47-61.

37 P Vigni, 'The Secretariat of the Antarctic Treaty: Achievements and weaknesses three years after its establishment' in G Triggs and A Riddell (ed) Antarctica: Legal and Environmental Challenges for the Future (British Institute of International and Comparative Law, London, 2007) 17-37.

${ }^{38}$ Article VI of the Antarctic Treaty states: "The provisions of the present Treaty shall apply to the area south of 60 degrees South Latitude, including all ice-shelves, but nothing in the present Treaty shall prejudice or in any way affect the rights, or the exercise of rights, of any State under international law with regard to the high seas in that area".

${ }^{39}$ United Nations Convention on the Law of the Sea (Montego Bay, 10 December 1982, in force 16 November 1994) 21 ILM 1261.

40 LOSC, Article 2, Article 55.

41 And for the unclaimed sector of Antarctica must do so for all states.

${ }^{42}$ Seven states claim territorial sovereignty over parts of Antarctica: Argentina, Australia, Chile, France, New Zealand, Norway and the United Kingdom.
} 
the construct of "New Zealand Fisheries waters" 43 (New Zealand), ${ }^{44}$ or declaration of an Exclusive Economic Zone (EEZ) (Australia) ${ }^{45}$ or EEZ-like constructs (Argentina and Chile), ${ }^{46}$ even if these cannot in practice be applied to non-nationals. Notwithstanding, in at least one case these assertions have attracted protest. ${ }^{47}$

\section{The Antarctic Marine Protected Area Process}

MPAs are a protected area category widely accepted and used throughout the world. The International Union for the Conservation of Nature (IUCN), the largest global environmental organisation, has actively campaigned for greater MPA representation and has set up a "Global Marine and Polar Programme".48 Some Members of the CAMLR Convention have been very active in the domestic designation of MPAs. Australia for instance has made significant advances in the areal extent and distribution of MPAs. ${ }^{49}$ The UK has designated the largest notake MPA in the world at the Chagos Islands, and whilst this has been contentious and legally challenged, is now considering the creation of three more large MPAs around Ascension, Pitcairn and the South Sandwich Islands. ${ }^{50}$ Whatever the motivation for these designations, in contrast other Member States such as Russia and China have been very slow to embrace the idea of MPAs. This is part of the background against which the Antarctic MPA process unfolds and we return to the wider international legal discourse around management of global ocean space below. Here we provide a brief overview of the events

\footnotetext{
43 Defined in Fisheries Act 1996, section 2, where "New Zealand fisheries waters means

(a)all waters in the exclusive economic zone of New Zealand:

(b)all waters of the territorial sea of New Zealand:

(c)all internal waters of New Zealand:

(d)all other fresh or estuarine waters within New Zealand where fish, aquatic life, or seaweed that are indigenous to or acclimatised in New Zealand are found"

${ }^{44}$ New Zealand has stated that it has "not declared a territorial sea or an exclusive economic zone in the waters adjacent to our claim in Antarctica (the Ross Dependency)" Commission for the Conservation of Antarctic Marine Living Resources, Report of the Thirty-Third Meeting of the Commission, Hobart, Australia, 20-31 October 2014, at paragraph 7.65.

${ }^{45}$ Australia Maritime Legislation Amendment Act 1994

http://www.comlaw.gov.au/Details/C2004A04696

${ }^{46}$ See WM Bush (ed.) Antarctic and International Law: A Collection of Inter-State and National Documents, Volume II (London, Oceana, 1982) 72, 202-203, 208-209, 448-449.

47 The United States in relation to the Australia EEZ proclamation: see US Department of State, National Claims to Maritime Jurisdictions: Limits in the Seas No 36, 8 ${ }^{\text {th }}$ Revision (Department of State, Washington DC, 2000).

48 The IUCN supports a wide range of activities that support international MPAs including: Protect Planet Ocean (MPA Portal); an IUCN-WCPA Marine Biome homepage; and an IUCN-WCPA High Seas Task Force. See:

http://iucn.org/about/work/programmes/marine/marine_our_work/marine_mpas/

${ }^{49}$ See: LK Kriwoken, 'Australian marine protected areas: Charting a course towards a representative system' pp171-182, in W Gullet, C Schofield and J Vince (eds.), Marine Resources Management (LexisNexis Butterworths, Australia, 2011)

50 See: IUCN 2015, Marine and Polar Program, available at:

http://iucn.org/about/work/programmes/marine/?18938/Mountingpressureformarineprotecti on
} 
relating to the attempts to build a systematic representation of MPAs in the Southern Ocean through CCAMLR. ${ }^{51}$

In 1989 the CCAMLR Ecosystem Monitoring Program (CEMP) was set up by the CAMLR Convention.52 By monitoring selected dependent species CEMP attempted to detect changes in the abundance of harvested species. Under CEMP "dependent species are marine predators for which species targeted by commercial fisheries are a major component of their diet". ${ }^{53}$ Indicator species include penguins, seabirds and seals. A network of sites is studied to compare fished areas and non-fished areas and fieldwork and data gathering is voluntarily undertaken by Member States. Whilst data gathering attempts to address annual ecosystem assessments, Constable has argued that "there is no indication of how these, or other types of data, could be used to demonstrate ecosystem effects of fishing and thereby initiate action by the Commission". ${ }^{4}$ Overall, despite the relevance of CEMP sites to compare fished and non-fished areas, their mandate has been too narrow to fully contribute to a Southern Ocean MPA system.

In 2005, the Scientific Committee of CAMLR (SC-CAMLR) decided that a bioregionalisation ${ }^{55}$ of the Southern Ocean was required to provide a theoretical basis for MPAs in the Convention area. The resulting workshop explored different approaches and classification methods that could support bioregionalisation. This important "proof of concept" concluded that bioregionalisation could indeed contribute to the development of an ecologically representative system of MPAs in the Southern Ocean.

Attention within the CAMLR Convention soon turned to an MPA designation on the South Orkney Islands Southern Shelf (SOISS) (Figure 2). Located close to the Southern Antarctic Circumpolar Current Front, the SOISS is highly productive and provides foraging and breeding grounds for seabirds and marine mammals. The area has high scientific value with long term decadal research undertaken on predator ecology, biodiversity and climate change. The South Orkney Islands are disputed between Argentina and the United Kingdom, but the claims are in

\footnotetext{
51 For a broader consideration of "Southern Ocean" MPA developments, which includes actions in metropolitan and subantarctic waters as well as the Antarctic Treaty area see: Scott 2013.

52 CEMP has two aims: detect and record significant changes in critical components of the marine ecosystem within the Conservation Area, to serve as a basis for the conservation of Antarctic marine living resources; and distinguish between changes due to harvesting of commercial species and changes due to environmental variability, both physical and biological. See: <http://www.ccamlr.org/en/science/ccamlr-ecosystem-monitoring-program-cemp> 53 Ibid.

${ }^{54}$ AJ Constable, WK de la Mare, DJ Agnew, I Everson and D Miller, 'Managing fisheries to conserve the Antarctic marine ecosystem: Practical implementation of the Convention on the Conservation of Antarctic Marine Living Resources' (2000) 57 ICES Journal of Marine Science 778-791 at 787.

${ }^{55}$ Bioregionalism is defined as a "process that aims to partition a broad spatial area into distinct spatial regions, using a range of environmental and biological information. The process results in a set of bioregions, each with relatively homogeneous and predictable ecosystem properties ... Bioregionalisation can assist in providing information on the location and distribution of species and their habitats, and is an important foundation for efforts to further understand, conserve and manage activities in the marine environment". See: S Grant, A Constable, B Raymond and S Doust, Bioregionalisation of the Southern Ocean: Report on Experts Workshop, Hobart, September (WWFAustralia and ACE CRC, Hobart, 2006) 1-45 at 6.
} 
abeyance as a result of the Antarctic Treaty. Notwithstanding the often acrimonious relationship between these two states, they were able to agree to the SOISS MPA. ${ }^{56}$ The MPA excluded areas of licensed krill fishing. Russia insisted on excising an area for exploratory fishing for crab. In 2009 CCAMLR designated an MPA in the region declaring that the area was representative of key environmental and ecosystem characteristics in the region and that it was recognised as a scientific reference area. ${ }^{57}$

With the adoption of its MPA framework Conservation Measure in 2011,58 the CAMLR Commission acknowledged the importance of MPAs in facilitating research and monitoring of Antarctic marine living resources. MPAs were apparently recognised as an important tool for sustainable marine management in the Southern Ocean. Notwithstanding this, no further MPAs have in fact been designated since the 2009 SOISS MPA, although two large areas have been formally proposed by Commission Members, and other areas have been canvassed at a more preliminary level.

\section{The Ross Sea}

The Ross Sea Region, located south of New Zealand, is one of the most remote parts of the Southern Ocean and has escaped direct anthropogenic alteration. ${ }^{59}$ The region supports high phytoplankton production making it the most productive stretch of ocean south of the Polar Front. ${ }^{60}$ It retains a full community of top-level predators including the Antarctic toothfish which is the dominant fish predator in the region, seabirds, seals and whales. Separate and combined proposals for an MPA in the region have been put forward by New Zealand and the USA. ${ }^{61}$ However, the 2012 CCAMLR meeting, the extraordinary meeting of the Commission in July 2013,62 and the 2014 CCAMLR meeting each failed to reach consensus on the proposals. Some Member States were concerned about the duration of the MPA, the process to support research and monitoring and the

\footnotetext{
${ }^{56}$ CCAMLR, 2009, "Protection of the South Orkney Islands southern shelf", Conservation Measure 91/03 (2009).

57 Antarctic Ocean Alliance, "Antarctic Ocean Legacy: A Vision for Circumpolar Protection,” Information Paper 51 submitted by ASOC at the Antarctic Treaty Consultative Meeting XXXV, Hobart 2012, p. 20. Available on the Antarctic Ocean Alliance website at: <http://antarcticocean.org/whats-at-stake/>.

58 CCAMLR, 2011, "General framework for the establishment of CCAMLR Marine Protected Areas", Conservation Measure 91/04 (2011).

${ }^{59}$ D Ainley, 'The Ross Sea, Antarctica, where all ecosystem processes still remain for study' CCAMLR: WG-EMM-02/60.Available from the CCAMLR website at:

<https://www.ccamlr.org/en/wg-emm-02/60>.

60 BS Halpern, S Walbridge, KA Selkoe, CV Kappel, F Micheli, CD'Agrosa, JF Bruno, KS Casey, C Ebert, HE Fox, R Fujita, D Heinemann, HS Lenihan, EMP Madin, MT Perry, ER. Selig, M Spalding, R Steneck, and R Watson, 'A global map of human impact on marine ecosystems' (2008) 319 Science, 948-952.

61 United States, 'A proposal for the Ross Sea region Marine Protected Area', CCAMLR-XXXI/40, (2012); New Zealand, 'A proposal for the Establishment of a Ross Sea Region Marine Protected Area', CCAMLR-XXXI/16 Rev.1; See also: United States, 'An MPA Scenario for the Ross Sea Region', SC-CAMLR-XXX/09 (2011); New Zealand, 'A Marine Protected Area scenario by New Zealand for the Ross Sea Region', SC-CAMLR6XXX/10 (2011).

${ }^{62} \mathrm{New}$ Zealand and the United States, 'A Proposal for the Establishment of a Ross Sea Region Marine Protected Area', CCAMLR-SM-II/04 (2013).
} 
implications for fisheries. ${ }^{63}$ Russia in particular stated its opposition to both proposals raising the issue of the size of the proposed MPAs, the arbitrary nature of their boundaries which it alleged did not take into account the distribution of ecosystem and biotypes along with the irrelevance of further closed areas to fishing when long-term area closures already exist within CCAMLR. ${ }^{64}$

\section{Eastern Antarctic Shelf}

The Eastern Antarctic Shelf (EAS) is an important feeding and breeding area for penguins, petrels, crab-eater seals and Antarctic krill (Figure 2). ${ }^{65}$ The region contains unique benthic and pelagic features, continental shelf pelagic ecosystems, and biodiversity hotspots for molluscs, seamounts, canyons and polynyas. Australia and France have jointly prepared proposals for seven MPAs in the EAS region at CAMLR Convention meetings in 2011, 2012 and 2013. This represents the first attempt to establish a network of MPAs at a regional scale in the CAMLR Convention Area.

\section{Preliminary Proposals}

Two other potential MPA areas have been scoped: in the Antarctic Peninsula, ${ }^{66}$ and the Weddell Sea. ${ }^{67}$ While the former was formally proposed by the European Union, it proved impossible to reach consensus on designation in 2012, ${ }^{68}$ and it appears to have been put on the backburner since, presumably because of the lack of progress on the Ross Sea and East Antarctica proposals. The Weddell Sea MPA discussion has so far been largely confined to the CCAMLR Scientific Committee's Working Group on Ecosystem Monitoring and Management (WGEMM). Interestingly, Russian specialists have responded (seemingly positively) to the German proposal. ${ }^{69}$

In addition to proposals made by Commission members, ENGOs have also made significant contributions. ${ }^{70}$ The Antarctic Ocean Alliance (AOA), ${ }^{71}$ an alliance of

\footnotetext{
63 See: CCAMLR news at: https://www.ccamlr.org/en/news/2014/international-meetinghobart-strengthens-antarctic-marine-conservation.

${ }^{64}$ See the statement of Russia in the Report of the Thirty-third meeting of the Commission, Hobart, Australia, 20-31 October 2014, CCAMLR XXXIII, Paragraph 7.50, available at: https://www.ccamlr.org/en/system/files/e-cc33-prelim.pdf.

${ }^{65}$ AJ Constable, B Raymond, S Doust, D Welsford, P Koubbi and AL Post, 'Identifying marine protected areas in data-poor regions to conserve biodiversity and to monitor ecosystem change: An Antarctic case study', WS-MPA-11/5, (2001) Hobart: CCAMLR. Available at:

https://www.ccamlr.org/en/ws-mpa-11/05.

66 European Union, 'EU Proposal for spatial protection of marine habitats and communities following ice shelf retreat or collapse in Subarea 88.3, Subarea 48.1 and Subarea 48.5', CCAMLRXXXI/30 (2012).

${ }^{67}$ K Tescke, B Dorschel, J Gutt, S. Haim, H Hellmer, K Jerosch, R Knust, K-H Kock, Schlüter, V Siegel and T Brey (Germany), 'Proposal for the establishment of a marine CCAMLR MPA in the Weddell Sea (Antarctica) - First conceptual outline' (2013) Document WG-EMM-13/22.

68 CCAMLR Secretariat, Report of the Thirty-First Meeting of the Commission (Hobart, Australia, 23 October-1 November 2012) at paragraphs 7.86 to 7.90 .

${ }^{69}$ AF Petrov, VA Bizikov, KV Shust and EF Uryupova (Russia), 'Background and criteria of establishment of Marine Protected Areas (MPA) in the Weddell Sea' (2014) Document WG-EMM$14 / 23$.

70 See: L Cordonnery and LK Kriwoken, 'Advocating a larger role for Environmental
} 
leading environmental and conservation groups, has been actively campaigning for MPAs. At the 2011 CCAMLR MPA workshop a number of proposals were put forward by AOA. The Alliance suggested that $40 \%$ of the Southern Ocean be designated as MPAs in "Antarctic Ocean Legacy: A Vision for Circumpolar Protection". ${ }^{72}$ The report makes reference to the ecological values of the areas and highlights the threats at a local, regional and circumpolar scale, and proposes protection of 19 areas in the Southern Ocean. ${ }^{73}$ It addresses large scale Southern Ocean processes critical for ecosystem and species protection, different environment types, as well as pelagic and seafloor features such as seamounts, ridges and troughs. Areas that are critical to the life-history stages of endemic species such as the Antarctic toothfish are included, as well as breeding and foraging grounds of other upper trophic level fauna, such as penguins and seals. It is argued that areas identified as warranting protection can also serve as critical climate reference areas and climate refuges for ice-dependent species. Areas particularly vulnerable to climate change, such as the Western Antarctic Peninsula, are identified as requiring protection.

\section{The MPA nexus between CCAMLR and the Madrid Protocol}

The Madrid Protocol streamlined the protected area system. Under Annex V (Area Protection and Management) an Antarctic Specially Protected Area (ASPA) can include any marine area protecting "outstanding environmental, scientific, historic, aesthetic or wilderness values, any combination of those values, or ongoing or planned scientific research". ${ }^{74}$ Antarctic Specially Managed Areas (ASMAs) can be declared where "activities are being conducted or may in the future be conducted", to "assist in the planning and co-ordination of activities, avoid possible conflicts, improve co-operation between Parties, or minimise environmental impacts". ${ }^{75}$

Parties are to "seek to identify, within a systematic environmental-geographical framework" a series of ASPAs areas presenting key characteristics, such as being "representative examples of major terrestrial, including glacial and aquatic,

\footnotetext{
Nongovernment Organizations in developing a network for Marine Protected Areas in the Southern Ocean' (2015) 46 Ocean Development and International Law 188-207.

${ }^{71}$ Within CCAMLR, the AOA provides input through ASOC. The AOA is an alliance of leading environmental and conservation groups. See the AOA's website at www.antarcticocean.org for information about membership, public campaigns and proposals for marine protected areas. Within CCAMLR, the AOA provides input through ASOC.

72 Antarctic Ocean Alliance, "Antarctic Ocean Legacy: A Vision for Circumpolar Protection," Information Paper 51 submitted by ASOC at the Antarctic Treaty Consultative Meeting XXXV, Hobart 2012, p. 20. Available on the Antarctic Ocean Alliance website at: <http://antarcticocean.org/whats-at-stake/>.

${ }^{73}$ These additional areas include: Antarctic Peninsula; Weddell Sea; Maud Rise, Bouvetoya, Del Cano - Crozet Region; Kerguelen High Seas region; Indian Ocean Benthic Environment; Amundsen and Bellingshausen Seas; and Peter I Island. See: Antarctic Ocean Alliance, 'Antarctic Ocean Legacy: A Vision for Circumpolar Protection', Information Paper 51 submitted by ASOC at the Antarctic Treaty Consultative Meeting XXXV, Hobart 2012, p. 51. Available at: http://antarcticocean.org/whats-at-stake/.

${ }^{74}$ Madrid Protocol, Annex V, Article 3(1).

75 Madrid Protocol, Annex V, Article 4(1).
} 
ecosystems and marine ecosystems". ${ }^{76}$ Annex V of the Madrid Protocol was the first ATS instrument to incorporate the notion of representativeness in the process of designating protected areas using a systematic environmentalgeographic framework. This is a significant departure from earlier approaches to designations which were sporadic, ad hoc and terrestrially-focused. ${ }^{77}$ With the inclusion of "any marine area" in Madrid Protocol Articles 2, 3 and 4, the scope of Annex $\mathrm{V}$ is not restricted to the terrestrial environment. However, protected areas specific to the marine environment have been largely ignored by the ATS. ${ }^{78}$ Only 10 ASPAs out of 73 have a marine component while 3 ASMAs out of 7 include the marine environment.

At the institutional level, the CEP and CCAMLR are the two main bodies responsible for the development of an Antarctic protected area system. The designation of MPAs within the ATS largely falls within the ambit of CCAMLR and its working groups. But Annex V of the Madrid Protocol plays an important role in the overall protected area system and of particular importance is the role of the CEP. Any representative MPA system must involve both CCAMLR and the CEP. It is, therefore, paramount that these instruments are integrated and decisions on MPAs harmonised.

Definitional differences of conservation in relation to rational or sustainable use of resources

The integration of CCAMLR and the Madrid Protocol and the harmonisation of decisions on MPAs may prove difficult to achieve given differences regarding the definition of 'conservation', particularly whether the definition is, or is not, inclusive of the notion of sustainable or rational use of resources. In the Guidelines for Implementation of the Framework for Protected Areas (the Guidelines), set forth in Article 3, Annex V of the Madrid Protocol, ${ }^{79}$ conservation and scientific research are listed as the two use categories (i.e., why the area is protected) against which a potential protected area needs to be tested. Conservation is defined under the Guidelines as follows: "Conservation embraces both protection and judicious use, management of biodiversity, intrinsic value and importance in maintaining the life sustaining systems of the biosphere: distinguished from "sustainable use" and "sustainable management" ${ }^{80}$

Although the Guidelines are merely hortatory, they demonstrate that the rationale for protected areas designation under ATCMs includes biodiversity

\footnotetext{
76 Madrid Protocol, Annex V, Article 3(2).

77 JD Shaw, A Terauds, MJ Riddle, HP Possingham and SL Chown, 'Antarctica's protected areas are inadequate, unrepresentative, and at risk' (2014) 12 PLOS: Biology 1-5.

78 The Antarctic Treaty System is defined in Article 1(e) of the Environmental Protocol as "the Antarctic Treaty, the measures in effect under that Treaty, its associated separate international instruments in force and the measures in effect under these instruments". The separate international instruments in force are: the Convention for the Conservation of Antarctic Seals (CCAS), CCAMLR and the Madrid Protocol.

${ }^{79}$ Resolution 1 (2000) - SATCM XII - CEP III, The Hague: Guidelines for implementation of the Framework for Protected Areas set forth in Article 3, Annex V of the Environmental Protocol. Accessible at: http://www.ats.aq. ${ }^{80}$ Resolution 1 (2000) - SATCM XII - CEP III.
} 
conservation as distinct from sustainable use. This is in contrast with CCAMLR, where the rationale for MPA designation relies on "conservation", which in turn is defined as including "rational use". ${ }^{81}$ Rational use and its incorporation into MPA planning have been discussed within the Scientific Committee of CCAMLR, where it was agreed that the Commission was competent to decide and define types of activities that constitute rational use and how to measure success in balancing rational use with conservation. ${ }^{82}$ In other words, CCAMLR's Scientific Committee appears to have accepted that decisions around this critical evaluation are matters of policy and politics, rather than scientific.

The interface between protected areas that may be designated under CCAMLR and those under ATCMs highlights overlapping methodologies and potentially conflicting rationales in the two fora.

\section{Division of competence between the CEP and CCAMLR over MPA designation}

In parallel to the adoption of Conservation Measures on MPAs within CCAMLR, there have been discussions within ATCMs regarding the operational ability of the CEP to propose ASMAs or ASPAs with a marine component. Any ASMA or ASPA with a significant marine component must be referred to CCAMLR prior to being considered in ATCMs. References are made to the cooperative relationship between the ATCM and CCAMLR, in particular Decision 4 (1998) - Marine Protected Areas and Decision 9 (2005) ${ }^{83}$ - Marine Protected Areas and Other Areas of Interest to CCAMLR that were adopted at ATCMs. More specifically Decision 9 defines what constitutes a significant marine component as:

... draft management plans that contain marine areas which require prior approval of CCAMLR are those:

a) in which there is actual harvesting or potential capability of harvesting of marine living resources which might be affected by site designation; or

b) for which there are provisions specified in a draft management plan which might prevent or restrict CCAMLR related activities. ${ }^{84}$

This division of competence between the CEP and CCAMLR over MPA designation narrows the scope of the CEP's involvement in the protected area system and reduces its capacity to implement the environmental provisions of the Madrid Protocol. It poses the question: how could the identification, management and monitoring of MPAs proceed in a manner that is consistent with the environmental management objectives that are common to both ATCMs and CCAMLR?

\footnotetext{
81 CCAMLR, Article II (2).

${ }^{82}$ See Paragraph 7.2 of the Report of the Twenty-Ninth Meeting of the Commission, Hobart, Australia, 25 October - 5 November 2010.

83 See Final report of the Twenty-Eighth Antarctic Treaty Consultative meeting, Stockholm, Sweden, 6-17 June 2005, p.369. Accessible from: http://www.ats.aq N.B: Decision 9 replaces Decision 4 which shall cease to be operative. ${ }^{84}$ Decision 9 (2005) ATCM XXVIII- Stockholm, available at: http://www.ats.aq/devAS/ats_meetings_meeting_measure.aspx?lang=e
} 
The MPA proposals under consideration at CCAMLR in 2012, 2013 and 2014 were designed to balance conservation and fishing interests. However, in reality they would inevitably displace some toothfish fishing and limit potential future access to Southern Ocean resources in these areas. Since the adoption of the CAMLR Convention, the number of fishing states has increased four-fold, correlating with the rise of toothfish fisheries. Although krill fisheries represent the largest catch, toothfish fisheries bring in 20 times more profit. Brooks notes that the failed outcomes of the 2013 CCAMLR meeting raise the question of whether national economic incentives in the Southern Ocean now overwhelm science and conservation values. ${ }^{85}$

\section{Implications for the future of the ATS}

The protracted debate over the designation of MPAs and the inability of CCAMLR to reach consensus raises important questions regarding the viability of the ATS as a successful model of governance. The threat posed by the contentious issue of MPA designation over which consensus cannot be achieved presents a significant challenge to the cohesiveness of the ATS. Potentially, an inability to resolve the MPA issue may erode confidence in the effectiveness of the ATS governance regime more generally.

\section{The Antarctic MPA imbroglio and the wider international legal discourse around management of global ocean space}

The discussion around Southern Ocean MPAs in Antarctica fora has not occurred in isolation from other Antarctic interests, nor from domestic moves in relation to MPA designation in Antarctic-active states both within their metropolitan territory and (for others) in relation to their subantarctic territories.

Critically, it has also been coupled with a wider international discourse around global ocean space, and in particular the protection of ABNJ.86 The two maritime zones constituting $\mathrm{ABNJ}$ in the terms of LOSC, 87 (i) the high seas beyond coastal state EEZs, ${ }^{88}$ and (ii) the Area, ${ }^{89}$ present particular political challenges for the ATS given unresolved territorial jurisdiction in Antarctica. Plainly, for the seven territorial claimants who believe themselves accordingly to be coastal states, ${ }^{90}$

\footnotetext{
${ }^{85} \mathrm{C}$ Brooks, 'Competing values on the Antarctic High Seas: CCAMLR and the challenge of Marine Protected Areas' (2013) 3 The Polar Journal, 277-300.

${ }^{86}$ See, e.g.: KM Gjerde, 'Challenges to protecting the marine environment beyond national jurisdiction' (2012) 27 International Journal of Marine and Coastal Law 839-847; K Houghton and J Rochette, Introduction: Advancing governance of areas beyond national jurisdiction" (2014) 49 Marine Policy 81-84.

87 United Nations Convention on the Law of the Sea (Montego Bay, 10 December 1982, in force 16 November 1994) 21 ILM 1261.

88 LOSC Part VII.

${ }^{89}$ LOSC Part I, Article 1(1) and Agreement to the Implementation of Part XI of the United Nations Convention on the Law of the Sea of 10 December 1982.

${ }^{90}$ Argentina, Australia, Chile, France, New Zealand, Norway and the United Kingdom.
} 
there are particular interests in play. But for these and other Antarctic Treaty states, including Russia and the United States who both reject the declared claims and reserve their own basis of claim, and others more clearly "nonclaimant", there is a concern not to revisit the delicate compromise arrived at in relation to territorial positions through Article IV of the 1959 Antarctic Treaty. ${ }^{91}$

As a result, the ATS as a whole has been ambivalent about the practical expression of LOSC prerogatives and duties in general within the Antarctic Treaty area. ${ }^{92}$ Thus, whilst the emerging norms of the global debate around ABNJ, and particularly duties and mechanisms in relation to protection of the marine environment, are certainly not repudiated within the Antarctic discourse, neither are they necessarily always welcome or perceived to be readily transferable to the Antarctic context without risk to other values and benefits states seek to secure.

\subsection{Domestic MPAs}

\subsubsection{Metropolitan}

The southern cone states surrounding Antarctica each have domestically designated MPAs. Whilst South Africa, ${ }^{93}$ and Argentina, ${ }^{94}$ appear to have less well developed national projects, Australia though its "National Representative System of Marine Protected Areas",95 New Zealand through its "network of marine protected areas", 96 and Chile through its "National Marine Network", 97

${ }^{91}$ Antarctic Treaty Article IV

Nothing contained in the present Treaty shall be interpreted as:

a. a renunciation by any Contracting Party of previously asserted rights of or claims to territorial sovereignty in Antarctica;

b. a renunciation or diminution by any Contracting Party of any basis of claim to territorial sovereignty in Antarctica which it may have whether as a result of its activities or those of its nationals in Antarctica, or otherwise;

c. prejudicing the position of any Contracting Party as regards its recognition or nonrecognition of any other State's rights of or claim or basis of claim to territorial sovereignty in Antarctica.

No acts or activities taking place while the present Treaty is in force shall constitute a basis for asserting, supporting or denying a claim to territorial sovereignty in Antarctica or create any rights of sovereignty in Antarctica. No new claim, or enlargement of an existing claim, to territorial sovereignty in Antarctica shall be asserted while the present Treaty is in force.

92 And Antarctica was not formally discussed in the course of LOSC negotiation - see, e.g. EJ Molenaar, DR Rothwell and AG Oude Elferink 'Interactions between global and regional regimes: trends and prospects' in EJ Molenaar, AG Oude Elferink and DR Rothwell (eds), The Law of the Sea and the Polar Regions: Interactions between Global and Regional Regimes (Martinus Nijhoff, Leiden, 2013) 389-417 at 391.

93 http://www.wwf.org.za/what_we_do/marine/mpas/sa_mpa_network/

94 http://wwf.panda.org/what_we_do/where_we_work/project/projects/?uProjectID=AR0856

${ }_{95}$ Australian Government Department of the Environment. Commonwealth Marine Reserves Background http://www.environment.gov.au/topics/marine/marine-

reserves/overview/background

96 Ministry for Primary Industries. Marine Protected Areas. http://www.fish.govt.nz/ennz/Environmental/Seabed+Protection+and+Research/MPA/default.htm See Map showing metropolitan and subantarctic MPAs at http://www.doc.govt.nz/pagefiles/524/marineprotected-areas-map.jpg 
are developing these systematically. France, as part of its 2007 strategy for the creation and management of MPAs, is committed to have at least $20 \%$ of the waters under its jurisdiction (including its overseas territories) covered by MPAs by $2020 .{ }^{98}$

\subsubsection{Subantarctic}

With the exception of the Scotia Arc island groups caught up in the UK-Argentine sovereignty dispute (noting the UK's effective jurisdiction over these groups), the subantarctic islands (all north of the Antarctic Treaty Area) are subject to undisputed national jurisdiction. Of the seven island groups south of the Antarctic Convergence and thus within the scope of the Southern Ocean used here, ${ }^{99}$ only one, Norway's Bouvetøya, does not have a substantial nationally designated MPA in place or under development. ${ }^{100}$ Some may be very large: the Heard and MacDonald Islands Marine Reserve covers 65,000 $\mathrm{km}^{2}, 101$ and the South Georgia and South Sandwich Islands MPA over a million $\mathrm{km}^{2}{ }^{102}$

Two of the key proponent states for Antarctic MPAs (New Zealand in relation to the Ross Sea MPA proposed with the United States; and Australia and France in relation to the East Antarctic MPA), are also amongst the seven claimant states, territorial sovereigns in the subantarctic (albeit the New Zealand islands are north of the Antarctic Convergence), and active in developing systemic MPA coverage in their metropolitan waters. Indeed, for Australia and New Zealand, the case for MPAs, at the national level, ${ }^{103}$ is seamlessly continuous from home waters to 'their' Antarctic claims (Figure 3). ${ }^{104}$ Without suggesting that territorial interests (including in the Antarctic) are the sole basis to these states Antarctic MPA advocacy (indeed, one might see these states as contributing to the 2002 WSSD commitment to develop a network of representative MPAs), ${ }^{105}$ it is

97 UNEP-WCMC (2008). National and Regional Networks of Marine Protected Areas: A Review of Progress. UNEP-WCMC, Cambridge http://www.unep.org/regionalseas/publications/otherpubs/pdfs/MPA_Network_report.pdf at 45

98 See the French National Strategy for the Creation and Management of Marine Protected Areas available at: http://www.developpement-durable.gouv.fr/IMG/pdf/13148-1_Strategienationale-aires-marines-protegees_GB-2.pdf.

${ }^{99}$ France has declared a reserve which includes a marine area of 15,700 $\mathrm{km}^{2}$ around Amsterdam, Saint-Paul, Crozet and Kerguelen Islands administered by Terres Australes et Antarctiques Francaises. See: http://www.taaf.fr/-La-Reserve-Naturelle-Nationale-des-Terres-australesfrancaises-

100 Scott 2013at 120-124.

101 Heard Islands and McDonald Islands Marine Reserve Management Plan (Australian Antarctic Division, Kingston, 2005).

102 Scott 2013.

103 Australia also has MPAs designated by State and Territory Governments as well as by the Federal Government, and the former may reflect quite different patterns.

104 Conceptually, scientifically, procedurally, across agency responsibility through to representation on maps.

105 Plan of Implementation of the World Summit on Sustainable Development http://www.un.org/esa/sustdev/documents/WSSD_POI_PD/English/WSSD_PlanImpl.pdf paragraph 32:

(c) Develop and facilitate the use of diverse approaches and tools, including the ecosystem approach, the e elimination of destructive fishing practices, the establishment 
reasonable to see these as a consideration. ${ }^{106}$

\subsection{The Arctic}

The circumstances of the Arctic are of course somewhat different from the Antarctic. ${ }^{107}$ Notably, with the exception of Hans Island, territorial sovereignty is agreed, and as a consequence coastal state jurisdiction is applicable. A large part of the Arctic Ocean thereby falls within national jurisdiction, whereas in Antarctica only the subantarctic islands north of the Antarctic Treaty Area do so. In the Arctic, in the absence of an RFMO an overarching regulatory mechanism is not available, ${ }^{108}$ and whilst there are a number of small nationally designated MPAs, "most of the Arctic marine environment remains without formal protected status". ${ }^{109}$ Further, the seeming limited development of MPA coverage in the Arctic (and for all their practical and jurisdictional differences there have often been resonances between the regions in relation to practical environmental management tools) has meant no obvious north polar initiatives for the south to keep up with. ${ }^{110}$

\section{$5.3 \mathrm{ABNJ}$}

The critical debates about environmental protection in ABNJ have included, variously, considerations around biodiversity, sustainable use, conservation and

of marine protected areas consistent with international law and based on scientific information, including representative networks by 2012 and time/area closures for the protection of nursery grounds and periods, proper coastal land use and watershed planning and the integration of marine and coastal areas management into key sectors;

${ }^{106}$ Such allegations however have been clearly denied by France which declared: "We cannot allow it to be said that a number of CCAMLR members, notably those who have EEZs in the Convention Area, are attempting, through plans to establish MPAs, to create a monopoly on fishing in the Southern Ocean". In Paragraph 7.67, Report of the Thirty-Third Meeting of the Commission, Hobart, Australia, 20-31 October 2014, available at: https://www.ccamlr.org/en/system/files/e-cc-xxxiii.pdf.

107 See: K Dodds and AD Hemmings 'Polar Oceans: Sovereignty and the Contestation of Territorial Resource Rights' in HD Smith, JL Suárez de Vvero and TS Agardy (ed), Routledge Handbook of Ocean Resources and Management (Routledge, New York, 2015) 576-591; AD Hemmings 'Common Challenge: International Equity in the Arctic and Antarctic' in P Kennedy (ed) The Arctic and Antarctica: Differing Currents of Change (New Zealand Institute of International Affairs, Wellington, 2015) [pages to be advised]; AD Hemmings 'The Antarctic Regime as a Model for the Arctic' in Lessons for the Arctic: Developing an International Normative Framework for a New Ocean (Centre for Strategic and International Studies and Brzezinski Institute for the Study of Geostrategy, Washington DC, forthcoming 2015) [pages to be advised].

${ }^{108}$ But note other mechanisms such as the Treaty Concerning High Seas Fisheries in the Barents Sea and the US prohibition of fishing in US Arctic waters. See M Byers, International Law and the Arctic (Cambridge University Press, Cambridge, 2013) 178-184, 213-215.

${ }^{109}$ S Lalonde, 'Marine Protected Areas in the Arctic' in EJ Molenaar, AG Oude Elferink and DR Rothwell (eds), The Law of the Sea and the Polar Regions: Interactions between Global and Regional Regimes (Martinus Nijhoff, Leiden, 2013) 85-111 at 98.

110 Perhaps supporting the judgment of "little interaction between the regulatory responses developed in the two polar regions" made by EJ Molenaar, DR Rothwell and AG Oude Elferink, 'Interactions between Global and Regional Regimes: Trends and Prospects' in EJ Molenaar, AG Oude Elferink and DR Rothwell (eds), The Law of the Sea and the Polar Regions: Interactions between Global and Regional Regimes (Martinus Nijhoff, Leiden, 2013) 389-417 at 410. 
operationalising the precautionary principle. ${ }^{111}$ These discussions have led, inter alia, to consideration of high seas MPAs. ${ }^{112}$ Interestingly, despite the substantive debate around marine protection in ABNJ having its roots in the rich grounds of the LOSC, as Scott shows the development of the idea of high seas MPAs has occurred elsewhere, through Agenda 21, the Convention on Biodiversity (CBD), RFMOs, the OSPAR Commission, and the UN ABNJ Working Group and CCAMLR. ${ }^{113}$ Indeed, the first high seas MPA designated was, as noted above, the South Orkney Islands Southern Shelf in 2009, by CCAMLR.

Curiously, despite this developmental sequence, in 2013 Ukraine (then at least with Russia in opposing further designation of MPAs by CCAMLR) argued that LOSC:

provides the opportunity for establishing MPAs only within the coastal waters in the areas of jurisdiction of those countries. Therefore, at this stage we cannot see any legal possibility for establishing MPAs in the high seas of the World Ocean containing areas for which CCAMLR is responsible. ${ }^{114}$

One has to suspect that one issue in the difficulties gaining agreement to MPAs in Antarctic waters is precisely the seamlessness of global ocean space so well captured by the originally Soviet term "The World Ocean". For states with global fishing interests, might Antarctica have appeared as the first domino?

\section{Analysis}

One of the striking things about the MPA debate and process has been that it did not occur under the auspices of the Madrid Protocol, where the Antarctic Protected Areas system is best (and most deeply) developed. Instead it occurred under the CAMLR Convention, which whilst plainly competent in relation to the Antarctic marine environment, had shown no commitment to the designation of MPAs in the first quarter century of its existence. The route through which it subsequently designated the first MPA in 2009, and its guidance in relation to MPAs in general in 2011, was the 'Conservation Measure' - a capacity that the CAMLR Commission had since the Convention entered into force in 1982. Plainly, the political incentive to proceed with a discussion around MPA designation in the Antarctic area was stimulated by the new and broader mandate for ASPAs and ASMAs that arrived with the entry into force of the Madrid Protocol in 1998, and perhaps particularly the entry into force of Annex V (Area Protection and

\footnotetext{
111 e.g. R Rayfuse, 'Precaution and the protection of marine biodiversity in Areas Beyond National Jurisdiction' (2012) 27 International Journal of Marine and Coastal Law 773-781; JA Ardron, R Rayfuse, K Gjerde and R Warner, 'The sustainable use and conservation of biodiversity in ABNJ: What can be achieved using existing international agreements?' (2014) 49 Marine Policy 98-108. 112 KN Scott, 'Conservation on the High Seas: Developing the Concept of the High Seas Marine Protected Areas' (2012) 27 International Journal of Marine and Coastal Law 849-857.

113 Ibid. at 851-854. See also KN Scott, 'Integrated Oceans Management: A New Frontier in Marine Environmental Protection' in DR Rothwell, AG Oude Elferink, KN Scott and T Stephens (ed) The Oxford Handbook of the Law of the Sea (Oxford University Press, Oxford, 2015) 463-490, 484-485. 114 CCAMLR Secretariat, Report of the Second Special Meeting of the Commission CCAMLR-SMII (Bremerhaven, Germany, 15 and 16 July 2013) at paragraph 3.26.
} 
Management) to that Protocol in 2002.

Whilst the Madrid Protocol provided the motive force, jurisdictional overlap between it and CCAMLR was resolved in favour of the latter having carriage of MPA proposals. Explicable as this pathway may be, it had consequences. It meant that the issue of MPA designation was consigned to the less competent body in relation to Area Protection (because it had no previous experience designating anything apart from ecosystem research areas), a body where there were likely to be conflicts between area protection and commercial fisheries interests. It meant that negotiation of MPAs would occur in a forum where core terms such as "conservation" would be qualified as including "rational use". Finally, it meant that the process of designation was assigned to a body where (as the failure to designate MPAs under its own capacities after 25 years suggests) there was not necessarily sympathy with the case for MPAs. That sympathy certainly developed subsequently, but this was from a standing start in institutional terms.

There are, in our judgement, also 'tactical' issues around the approach taken in the designation of actual MPAs. Whereas, following detailed technical level discussions around generic issues, the initial approach was to propose, and successfully designate, a single MPA (SOISS MPA) in 2009.Thereafter the sequential approach was abandoned and multiple proposals were launched (the Ross Sea and East Antarctica proposals which have attracted most attention, plus discussions around others in the Antarctic Peninsula and Weddell Sea). We wonder whether seeking to progress even two (the Ross Sea and East Antarctica) proposals in parallel was a tactical error. Given that opposition to MPA designation could be expected, and was early known, the spectre (as opponents might see it) of a picket of MPAs around half the circumference of the continent was likely to raise fears of a more systematic restraint on fishing activity. ${ }^{115}$ Whilst this seems never to have been the intention of at least the state proponents concerned, the scale of the proposals allowed opponents to cast the project in these terms. The commitment - and the objective environmental need on all scientific best evidence - to develop a systematic coverage of MPAs, which surely always required multiple areas, did not require that these all be designated together. The systematic and representative coverage of MPAs could have been achieved through serial or incremental designation of the component MPA areas. Not to have chosen this route, appears to us to have added to the difficulties.

What 'strategic' lessons might one see in the history and modalities of the discourse and negotiations within ATS fora around Antarctic MPAs, over the past decade? Firstly, we suggest, some discouraging lessons in relation to assumptions and expectations of a structural sort. We think it has been fair to say that the normative assumptions have included:

(i) Confidence that a scientifically underpinned "evidence-based" process in relation to MPAs would lead inexorably into a clear policy response. This

115 The picture may appear even more forbidding for fishing states if they consider the 19 circumpolar areas proposed by environmental NGOs. See, e.g. http://antarcticocean.org//wpcontent/uploads/2013/03/11240-AOA-19-Areas-Map-FINAL.pdf 
assumption predicated, quite reasonably, on both the generally privileged and entrenched role of science and the insights it provided, in the formal management of the area across the ATS,116 and specifically the deep formal scientific structure and role built into the CAMLR Convention and its operating practices as an institution; ${ }^{117}$ and

(ii) Both within and outside the ATS, a confidence that whatever the difficulties posed by attempts to designate large open ocean area MPAs in Antarctica, this was the least hard place to try in a global context. This assumption drew in part on the previous "evidence based" assumption, the fact that the CAMLR Convention's mandate was broader and its institutional development deeper than any RFMO, and also on the supposition that Antarctica was a less complicated place where commercial and broader economic interests and perceptions of critical national rights and costs were at a lower level than elsewhere. Nobody assumed that these interests did not occur, but it was assumed that the particular history and circumstances of the Antarctic meant they were less developed here. One might term this the "Antarctic-first" assumption, wherein the achievement of MPAs in this region has, in addition to its regional significance, a capacity building, proof of concept and precedent setting value globally. Whilst, plainly, MPA designation has arisen in other multinational fora, such as the 1992 OSPAR Convention, ${ }^{118}$ this is a very different multilateral treaty. It is narrowly regional, it concerns waters immediately adjacent areas within national jurisdiction, and it involves European states with broader and deeply embedded political, legal and institutional relationships. It was in terms of practical international politics much less of a precedent-setter than the Antarctic would be, by virtue of the wider and more globally distributed membership of the ATS instruments.

In practice, neither assumption held. Whilst the ATS had little difficulty developing the legal and institutional basis that would allow the designation of large MPAs, ${ }^{119}$ and was seemingly able to come (via the CAMLR Scientific Committee) to general conclusions about the scientific case for, and shape of, an

\footnotetext{
116 See, inter alia, the Antarctic Treaty, CCAMLR, Madrid Protocol; the Rules of Procedure under which ATCMs, the CAMLR Commission and Scientific Committee and the Madrid Protocol's Committee for Environmental Protection operate; and the mechanisms granting access and advisory roles to SCAR.

117 Including: the obligation of the Commission under Article IX 1(f) of the Convention to "formulate, adopt and revise conservation measures on the basis of the best scientific advice available, subject to the provisions of paragraph 5 of this Article" (paragraph 5 refers to measures taken under Article IX of the Antarctic Treaty or existing fisheries commissions for species which may enter the CCAMLR area); the establishment of the Scientific Committee under Article XIV and the specification of its purposes in Article XV.

${ }^{118}$ Convention for the Protection of the Marine Environment of the North East Atlantic (Paris, 22 September 1992, in force 25 March 1998) 2354 UNTS 67.

119 Through the mandating in the Madrid Protocol of marine areas as appropriate foci for protected area designation, the even earlier capacity under CCAMLR Article IX 2(g) via conservation measures to close particular areas, and the adoption by such measures of both guidance in relation to MPAs in general through Conservation Measure 91-04 (2011), and in relation to the South Orkney Islands Southern Shelf MPA through Conservation Measure 91-03 (2009).
} 
Antarctic MPA system, ${ }^{120}$ these achievements proved an insufficient platform for the policy response of actually designating areas. Once the debate had moved beyond the technical and architectural stages, objections of a substantive policy sort became evident. States were agreeable in principle to the designation of MPAs, but not to the actuality of designating particular areas.

At this stage three sorts of arguments emerged: first that suddenly, apparently, there were serious legal impediments to CCAMLR actually doing what had previously been accepted that it could do, and in relation to SOISS that had actually been done.121 Secondly, that the scientific case was not, supposedly, robust enough after all. Alongside protestations of in-principle commitment to the designation of MPAs, it was argued that we needed more evidence. The issues seem well captured in the New Zealand statement in 2014:

Russia has suggested that there is insufficient science to support the Ross Sea region proposal, and that there is a need for further scientific research before an MPA can be designated in the Ross Sea region. I would refer Members to SC-CAMLR-XXXIII/BG/23 Rev. 1 and SC-CAMLR-IM-I/08 which clearly set out the significant body of science supporting the RSRMPA proposal. In our view, the scientific evidence supporting the MPA proposal has been comprehensively assessed and endorsed by the Scientific Committee (SC-CAMLR-IM-I, paragraphs 2.31 to 2.33) and accepted by the overwhelming majority of the CCAMLR membership. ${ }^{122}$

The difficulty (or advantage, depending on your policy stance) of this was that it almost certainly meant the postponement of any reconsideration for some years, as the whole scientific and technical case was again litigated through the labyrinth of the CAMLR Scientific Committee and its sub-committees, with assorted workshops and exchanges - a point New Zealand also alluded to:

Moreover, Russia's argument overlooks that CCAMLR has agreed to an approach to the establishment of a representative network of MPAs based on "best available" scientific evidence (paragraph 2 of CM 91-04 and Article IX.1(f) of the Convention). This reflects a precautionary approach whereby the best available scientific evidence is used so that the need for ever more science cannot be used to indefinitely defer action to protect the environment. ${ }^{123}$

A third argument arose that there were other motives on the part of the proponents of the particular MPAs under consideration that had more to do with

120 Conservation Measure 91-04 (2011).

121 See above statement by Ukraine [source at Note 100] where, four years after it had joined the CCAMLR consensus that allowed designation of the SOISS MPA it challenged CCAMLR's legal standing for designating MPAs "in the high seas". See also Russia's 2013 statement on "confusion regarding the concepts of [MPAs] and areas, regions or sub-regions closed .... In accordance with Article IX of [CCAMLR]" CCAMLR Secretariat, Report of the Second Special Meeting of the Commission CCAMLR-SM-11, Bremerhaven, Germany, 15-16 July 2013 at paragraph 3.18. 122 Commission for the Conservation of Antarctic Marine Living Resources, Report of the ThirtyThird Meeting of the Commission, Hobart, Australia, 20-31 October 2014, at paragraph 7.65. 123 Ibid. 
national interest and geopolitics than environmental management of the Antarctic marine environment. In part these fears arise as part and parcel of antagonisms that go well beyond specifically Antarctic issues and relationships. With increasing tensions between western states and China, and a resumption of tensions between western states and Russia, globally, it is relatively easy for differences in the Antarctic to polarize positions. In the case of Russia, and the deterioration of relationships around the situation in Ukraine and elsewhere, it was then much easier for Russia to argue a relationship between Antarctic claimant states' territorial interests and MPA designations. ${ }^{124}$ The congruence between the Ross Sea and East Antarctic MPA proposals and proponents and the areas of territorial claim of New Zealand, Australia and France, had earlier been noted by observers sympathetic to MPA designation, ${ }^{125}$ on tactical mis-step grounds. Further, to the extent that much environmental management practice in Antarctica has been sourced from western state domestic practice, or through international processes largely driven from western states, it has been possible for resentment around the further 'imposition' of environmental values to come to the fore. On the other side, is the perception that 'the usual suspects'126 are foot-dragging in relation to environmental protection. So, elements of chauvinism and cultural difference arise. Whilst it is difficult to precisely identify the level of significance of these factors in relation to the MPA imbroglio, we are persuaded that they have been factors.

The ATS is a complex suite of instruments extending across a range of issues. Through these instruments various interests and values are addressed. But State Parties are not homogenous in either the priority they attach to each of these, or in their interpretation of the rights and duties to which they have 'signed-up to' in the Antarctic instruments. The western framing of the Antarctic MPA discourse has been that it is about environmental and resource protection, and that as night follows day CCAMLR will necessarily concur in securing this protection. The difficulty has been that other interests and values apart from environmental and resource protection have intruded, and these are not necessarily commensurable with environmental protection and resource protection; or are at least given priority over these in the eyes of particular states. These other interests include: freedom of marine harvesting; freedom of action more generally in Antarctica on a principle of de minimus governance there; and strategic geopolitical interests that include particular sensitivities to territorial or hegemonic aspirations on the part of others. This has revealed itself in themes evident in recent confrontations in relation to activities in the Southern Ocean: the MPA saga, and the question of the regulation of whaling under the International Whaling Commission. The two themes are, firstly, whether an instrument set up to manage an activity is allowed to manage by

\footnotetext{
${ }^{124}$ Russia, 'Principal provisions of the Russian Federation regarding the proposal to establish an MPA in the Ross Sea' CCAMLR-XXXIII/26 (2014); Russia, 'Marine Protected Areas in the Antarctic Treaty System' CCAMLR-XXXIII/BG/09 (2014); VV Lukin, 'Russia's current Antarctic policy' (2014) 4(1) The Polar Journal 199-222 at 220.

125 'Global Insider: Marine Reserve Failure Undermines Antarctic Treaty States' Credibility' World Politics Review, 7 November 2012.

126 With varying degrees of public profile, the states most resistant to the designation of further large Antarctic MPAs have included China, Japan, Russia, South Korea and Ukraine.
} 
stopping the activity (absolutely in relation to so-called 'scientific whaling'; in discrete areas in relation to MPA designation under CCAMLR); or whether (as the proponents of the harvesting activity argue) the raison d'être of these instruments and institutions is the activity and therefore a priori legitimate. ${ }^{127}$ This is a quite critical assessment of the legitimate scope of interpretation of these instruments. Secondly (but necessarily coupled with the first), can existing legal instruments change in an evolutionary manner to make them fit new circumstances or sensibilities, or are they essentially immutable and can only be replaced in toto (which of course those in favour of the status quo will not anyway assist in achieving)?

The MPA imbroglio suggests that we face quite considerable differences in assessment of what the ATS is about and how it should function, amongst its established member states. That this has been sprung on us in the course of the MPA process perhaps speaks to a lack of realism hitherto about the actual level of commonality of purpose within the ATS more broadly.

The proposition that whatever the difficulties, Antarctica was in some sense an easier place than most to designate MPAs, has, as we have noted, been proven erroneous. In part we think that this reflects the naivete of the idea in the first place. The critics of extended MPA coverage on the high seas would hardly be blind to the potential global precedent value of an Antarctic MPA model. In the absence of the sort of LOSC implementing agreement in relation to MPAs (an analogue to the Fish Stocks Agreement) suggested by Scott, ${ }^{128}$ the halting process of designating MPAs under various instruments and institutions risks setting 'unfortunate precedents' which in their very unpredictability are seen as threatening to traditional fishing states. If this analysis is correct, the opposition to MPA proposals in Antarctica is, whatever challenges particular interests see them posing there, a challenge of global import since it may lead to similar developments in other ABNJ nowhere near the Antarctic. The fact that the Ross Sea MPA attracted, from the United States as co-sponsor, high profile advocacy by successive Secretaries of State - which in relation to other Antarctic issues might be considered a game-changer - here simply flagged the high stakes involved, and brought into play high policy decision-making in opponent states, exacerbated as we have noted by out of area issues.

Anyhow, the hope that Antarctic MPAs designated through a regional agreement (CCAMLR) might prove a way to catalyse high seas MPA designation more generally seems now to have been dashed. Perhaps the issue has now to be tackled more generically, in order to generate the confidence that will allow wider acceptance.

In this article we have sought to elucidate the nexus between CCAMLR and the Madrid Protocol in relation to the project of designating MPAs. As the foregoing analysis suggests, we conclude with the realization that other and less tractable

\footnotetext{
127 See discussion on this in K Dodds and AD Hemmings, 'Britain and the British Antarctic Territory in the wider geopolitics of the Antarctic and the Southern Ocean' (2013) 89 International Affairs 1429-1444 at 1434.

128 Scott 2012 at 857.
} 
issues than the institutional relationship of two key elements of the Antarctic Treaty System have been in play. These, in our judgment, are significant factors in the MPA "imbroglio". We conclude with an examination of what may now be done, from the point of failure at which we find ourselves in relation to Antarctic MPA development, to materially improve the prospects for gaining international agreement to a representative set of open ocean MPAs in Antarctic waters over the coming decade.

\section{Conclusions}

Given the threat to the cohesiveness and effectiveness of the ATS posed by the lack of progress on MPA designation, it seems that there is a need to reassess the commonality of purpose within the ATS through formal discussions on Antarctic values. ${ }^{129}$ In short, Parties may need to have some quite fundamental discussions about the purposes of the Antarctic regional regime in the $21^{\text {st }}$ Century, difficult as this may prove. If greater cooperation between (or integration of) CCAMLR and the Madrid Protocol would materially improve the prospects for reaching consensus on designation of MPAs in the Southern Ocean, what type of modus vivendi would be required? Could it entail some resolution of the conflicting values underlying the operation of the Madrid Protocol and CCAMLR in so far as the definition of the term "conservation" is concerned - whether it is inclusive or exclusive of rational use? Harmonizing the position of member states across both ATS fora is essential in determining whether MPAs should be used as a biodiversity conservation or as a fisheries management tool. Desirable as this seems, it is unlikely to occur given the narrow interpretation of the Madrid Protocol's mandate in relation to the designation of MPAs, and the deliberate policy choice Antarctic states have made in relation to separating responsibility for the marine and quasi-terrestrial parts of Antarctica.

If we still have hope of making progress on MPAs within the existing CCAMLR structure, how could further progress be made? Putting political pressure on CCAMLR to progress the MPA discourse needs to be supported by both internal and external actors, both states and accredited "Observer" entities. As observers, IUCN and ASOC already play an active role within CCAMLR when circulating information papers and making statements during the CCAMLR proceedings. Increased ENGOs participation in key working groups such as the Ecosystem and Monitoring Working Group where MPA proposals are conceptualized and debated could be a desirable option given their track record in improving Antarctic governance, in line with the environmental principles that member states have agreed to implement. ${ }^{130}$ Unless this continues, one would have to suppose that the serial failures in relation to MPA designation over recent years will encourage the hitherto proponent states to allow the issue to lose profile. These states are unlikely to do anything as crude as formally removing their proposals from the agenda of the CAMLR Commission, since that would be to concede failure formally, but soft-peddling would, whilst face-saving, have the

\footnotetext{
${ }^{129}$ Note the work undertaken by the SCAR Humanities and Social Sciences Expert Group focusing on 'Values in Antarctica: Human Connections to a Continent', available at: http://antarcticassag.org/projects/

130 Cordonnery and Kriwoken 2015.
} 
same effect. Observers are likely also critical in ensuring that states do not rectify the failure to reach consensus on MPAs by agreeing to something that whilst labeled "MPA" has no utility in actually improving environmental protection in the Antarctic marine environment.

Another approach to reach consensus over MPA designation within CCAMLR could be to revive traditional polar diplomacy by which some key states, such as Norway for example, have acted as bridging states to bring together the initially most opposed member state views. Given Norway's historic engagement in Antarctic regime development (including its important role in finding a middle way to what became the Madrid Protocol), its claimant position, the fact that it was not itself one of the active proponents of the East Antarctic MPA proposal (despite this being adjacent to its claimed area of Dronning Maud Land), and its particular relationship with Russia in the Arctic,131 it is in a good position to fulfill this mission. In addition, our examination of Norway's position and formal statements over the last three CCAMLR meetings indicates that Norway may already have started to play this facilitating role. ${ }^{132}$ Whether this role is best continued informally, or should become a more formal role, is a nice diplomatic question. If this was to be the case, it may require for Norway to convene extraordinary meetings beyond CCAMLR dedicated to resolving outstanding MPA issues such as legality, design, duration and monitoring.

The difficulty is that after such protracted and intense consideration within CCAMLR fora, over now many years, fatigue may have set in. Reinvigorating a CCAMLR debate with any prospects of this actually leading to further MPA designation in even the medium term (say 5-10 years) is, realistically a challenge. Ultimately one has to ask what is likely to change in relation to the positions of key states' positions; and given the contributing factors in these positions, can such change be reasonably expected to arise within the CCAMLR arena? The out of area facets are entirely beyond the mandate of the CAMLR Commission to consider, let alone resolve. Even the substantive differences of interpretation in relation to the Convention as a legal instrument, and the underlying differences in purpose and values into which this segues, are matters that may be seen as so sensitive in relation to ATS stability that nobody (whichever side of the fence they find themselves in relation to MPAs) will wish to tackle them.

Our judgment is that the negotiation of MPA designation within CCAMLR fora, may for the moment have run its course. If this is so, are there any alternatives to a grudging acceptance of there being no prospects there for perhaps a decade? We think that there are.

\footnotetext{
131 Including the 'Treaty between the Kingdom of Norway and the Russian Federation concerning Maritime Delimitation and Cooperation in the Barents Sea and the Arctic Ocean" https://www.regjeringen.no/globalassets/upload/ud/vedlegg/folkerett/avtale_engelsk.pdf 132 See Norwegian statements: Commission for the Conservation of Antarctic Marine Living Resources, Report of the Thirty-Third Meeting of the Commission, Hobart, Australia, 20-31 October 2014, at paragraph 7.59; Report of the Thirty-Second Meeting of the Commission, Hobart, Australia, 23 October-1 November 2013 at paragraphs 7.11, 7.29, 7.48; Report of the Second Special Meeting of the Commission CCAMLR-SM-11, Bremerhaven, Germany, 15-16 July 2013 at paragraph $3.23,3.53$;
} 
The difficulties around MPA designation in the Southern Ocean are consistent with the apparently slight progress towards MPA designation in ABNJ in general. This suggests that more substantive generic problems with MPA designation may underpin the particular difficulties found in Antarctica. That this is so may have been obscured by the fact that in 2009 an MPA (SOISS) was designated. But apart from that success, the fact of regional architecture which in a formal sense promised to facilitate the process has not proved decisive. Perhaps progress on Antarctic MPAs is now contingent on tackling ABNJ MPAs more generally. To move forward it may be necessary to resolve the MPA discourse at the global level as suggested by Karen Scott, ${ }^{133}$ whereby an implementing agreement to LOSC could be modelled on the 1995 Fish Stocks Agreement. ${ }^{134}$ This implementing agreement would be dedicated to High Seas MPAs both outside and within the context of RFMOs. Clearly CCAMLR would fall within that scope. This process will surely present its own challenges, and likely has an extended timeline. However - to focus solely on its relevance for the Antarctic region - it would take the sting out of the present regional debate within the CAMLR Commission, it would ensure the debate was of significance for all the Parties to the Antarctic debate precisely because it would necessarily relate to their interests in other ocean areas, and in so doing it would more readily allow concession and accommodation than now seems likely within the CAMLR Commission. To switch our focus to the global level and a project of securing a new general agreement in relation to MPAs in ABNJ is not to require that all work and thought around MPAs should cease within CCAMLR, or to suggest that this forum has nothing to contribute to the global debate. On the contrary, the technical work already done through the CAMLR Scientific Committee, the Commission, and by the State Parties who have articulated positions around MPAs, must surely be seen as a critical source of input into a more general process. Further, in the long run Antarctica must be integrated into a truly global network of MPAs. Instead of pursuing an increasingly forlorn hope that something can, somehow, be cobbled together by more of the same process within the ATS, this may be where we now need to turn.

\section{Acknowledgements}

The authors thank the anonymous referees for their helpful comments on the manuscript. ADH extends appreciation to Kees Bastmeijer, Sanjay Chaturvedi, Donald R. Rothwell, Karen N. Scott, Juan Francisco Salazar and Tim Stephens, with whom issues of Antarctic marine management and policy have been discussed over many years. LKK acknowledges the following Antarcticans for their contribution and expertise on matters related to Antarctic law, policy and environmental science: Bruce Davis, Rob Hall, Marcus Haward, Julia Jabbour, Andrew Jackson and Tom Maggs. However, none of these people should necessarily be implicated in the particular assessments and positions adopted in

\footnotetext{
133 Scott 2012.

${ }^{134}$ Agreement for the Implementation of the Provisions of the United Nations Convention on the Law of the Sea of 10 December 1982 Relating to the Conservation and Management of Straddling Fish Stocks and Highly Migratory Fish Stocks, New York, 4 August 1995, in force 11 November 2001 (1995) 34 ILM 1542.
} 
the paper

Figure 1 - Antarctica and the Southern Ocean defined by the CCAMLR boundary

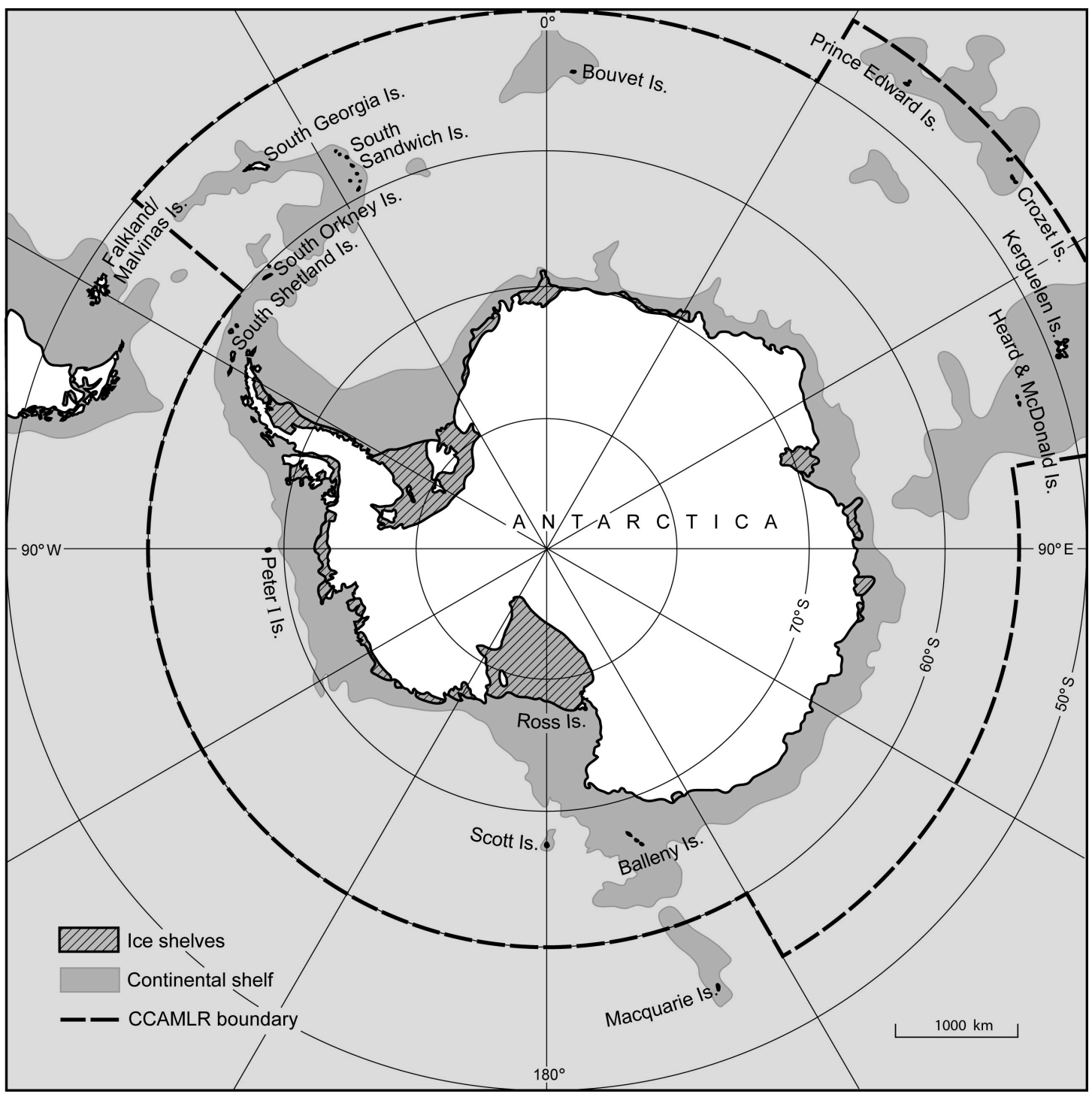


Figure 2 - MPA Areas Proposed or Designated

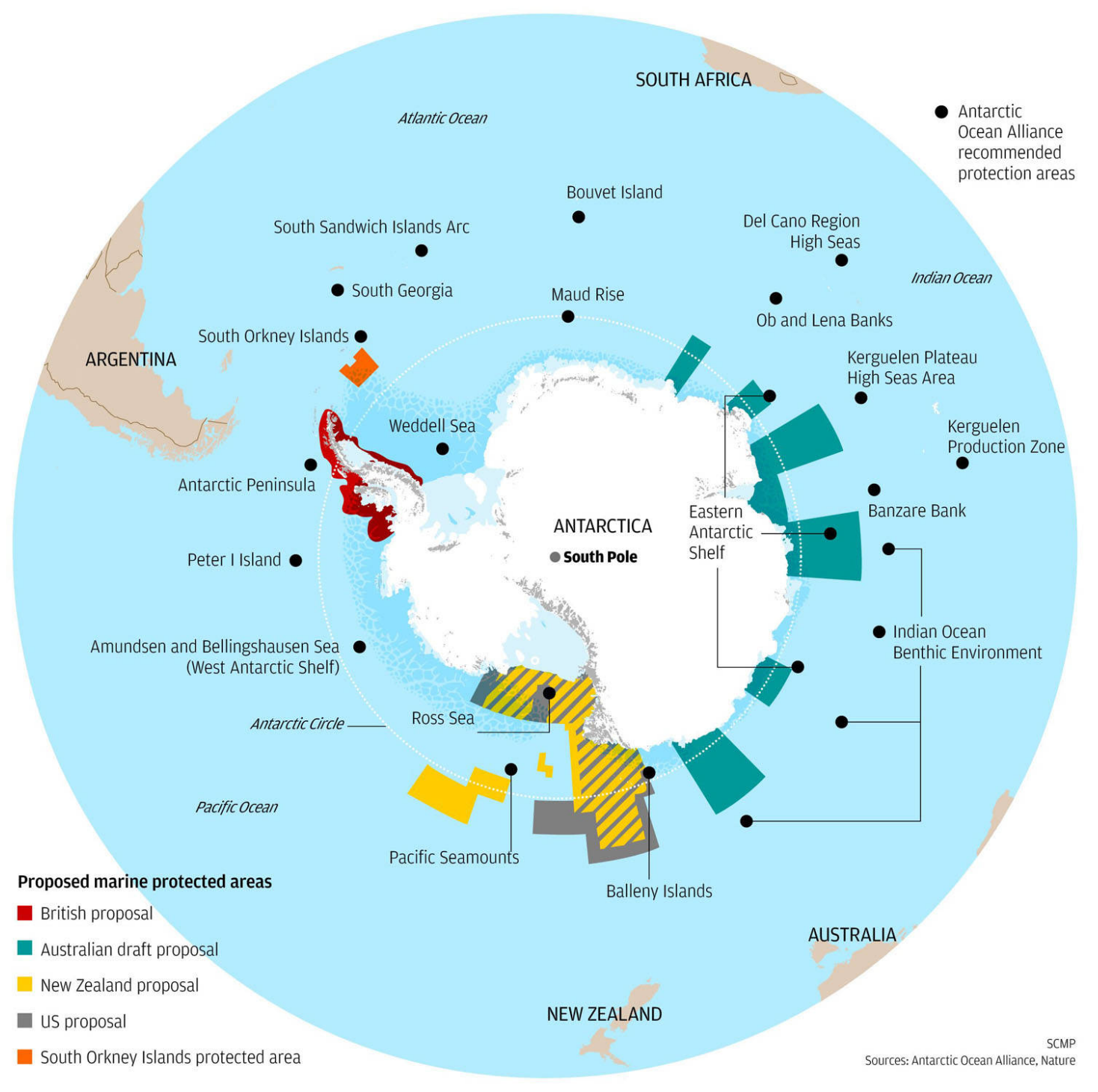

Source: South China Morning Post, 3 November 2012 
Figure 3 - Seamless National (Federal) approaches to MPAs from Metropolitan, through Subantarctic to Antarctica waters (the case of Australia)
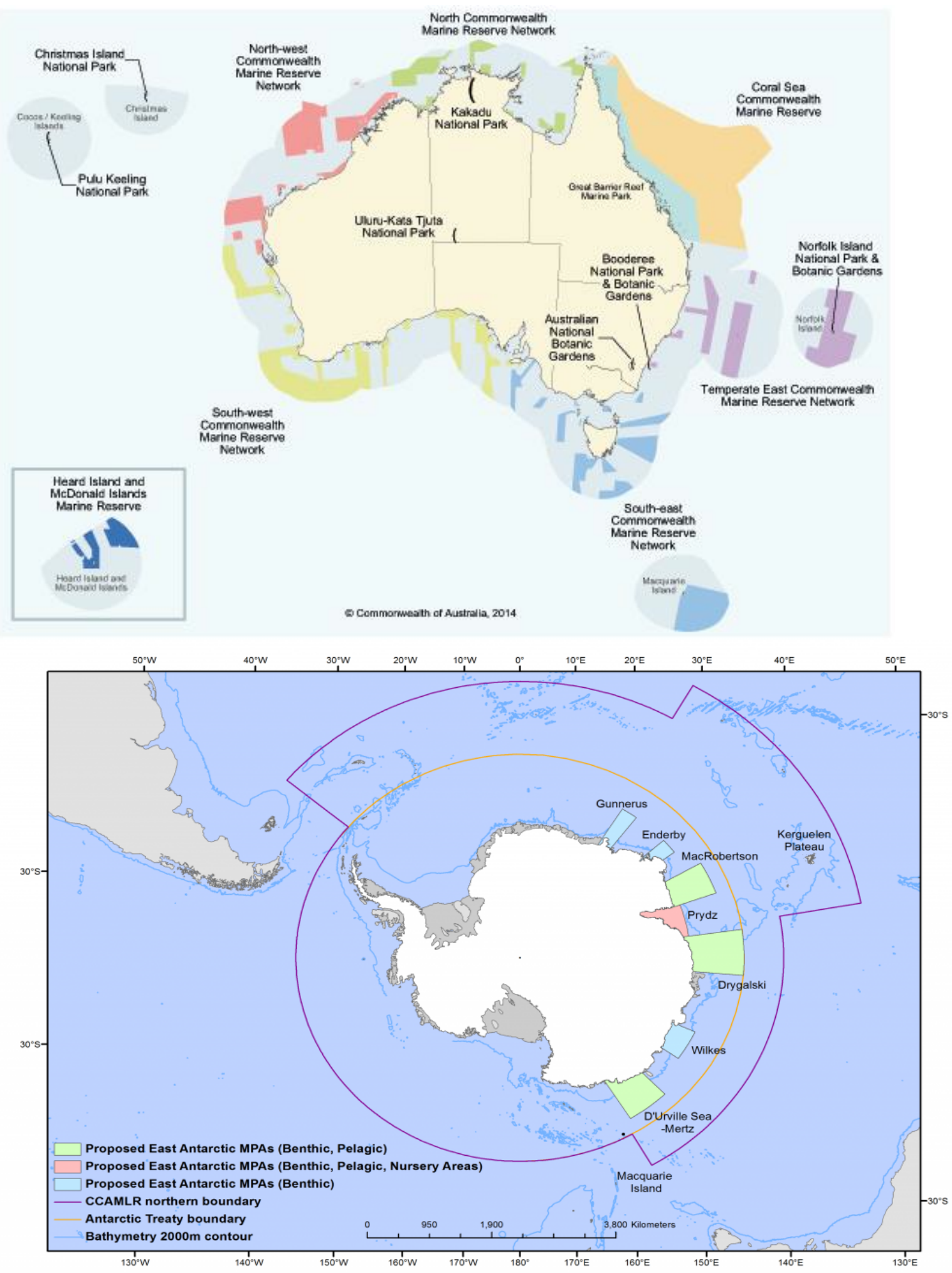

Source: Commonwealth of Australia, Department of Environment and Australian Antarctic Division 